\title{
EVALUATION OF CLINICAL AND BIOCHEMICAL FEATURES OF \\ PATIENTS WITH ATYPICAL PARATHYROID ADENOMA: A \\ RETROSPECTIVE STUDY
}

\section{Sefika Burcak POLAT 1, Mehmet KILIC 2, Cevdet AYDIN 1, Didem OZDEMIR 1, Nuran SUNGU ${ }^{3}$, Reyhan ERSOY ${ }^{1}$, Bekir CAKIR ${ }^{1}$}

\author{
1 Yildirim Beyazit University, Ataturk Education and Research Hospital, Endocrinology and Metabolism Department Ankara, \\ Turkey \\ 2 Yildirim Beyazit University, Ataturk Education and Research Hospital, General Surgery Department, Ankara, Turkey \\ ${ }^{3}$ Yildirim Beyazit University, Ataturk Education and Research Hospital, Pathology Department, Ankara, Turkey
}

\section{OBJECTIVES}

> Primary Hyperparatyhyroidism (PHPT) is usually caused by single or multiple adenomas and cancer is rare accounting for less than $1 \%$ of all presentations.

$>$ The presence of certain cytological, and architectural features such as adherence to adjacent organs, a solid growth pattern, broad bands of fibrosis, cytological atypia, and an irregular growth contour do not indicate malignancy but are recognized as atypical features encountered more commonly in malignant than benign tumors.

$>$ Tumors that demonstrate these atypical features and do not fulfill criteria for carcinoma can be classified as atypical adenomas

D Herein we aimed to evaluate the clinical and biochemical features of the patients histopathologically diagnosed with an atypical parathyroid adenoma.

\section{METHODS}

$>$ Our endocrine database was searched retrospectively for the patients with operated PHPT and diagnosed with atypical adenoma.

$>$ Demographic, clinical and biochemical data of the patients were recorded. A control group was formed from the patients who were also operated with the diagnosis of PHPT and classical parathyroid adenoma was detected histopathologically.

\section{RESULTS}

$>$ There were sixteen patients in the atypical adenoma group and thirty patients in the control group.

$>$ Age and gender distribution of the patients were similar in between groups with female predominance

> Serum $\mathrm{Ca}$ and $\mathrm{P}$ levels were also similar where as preoperative serum PTH, ALP and urinary $\mathrm{Ca}$ excretion were significantly higher in patients with atypical adenoma $(p<0.001$, $p<0.001$ and $p=0.021$, respectively)
$>$ Adenoma size was significantly higher in the atypical adenoma group compared to controls $(p=0.006)$ and cystic degeneration and isoechoic appearance on USG were more prevalent among the atypical adenomas $(p=0.016)$.

\begin{tabular}{|c|c|c|c|}
\hline & $\begin{array}{l}\text { Atypical } \\
\text { adenoma(n=16) }\end{array}$ & Control $(n=30)$ & $\mathbf{p}$ \\
\hline Age & $51.19 \pm 13.55$ & $53.26 \pm 12.90$ & 0.61 \\
\hline Sex (F/M) & $9 / 7$ & $6 / 24$ & 0.08 \\
\hline $\mathrm{Ca}$ & $11.75 \pm 1.62$ & $11.40 \pm 1.00$ & 0.37 \\
\hline $\mathbf{P}$ & $2.43 \pm 0.63$ & $2.66 \pm 0.61$ & 0.24 \\
\hline PTH & $614.66 \pm 55.48$ & $207.83 \pm 123.60$ & $<0.001$ \\
\hline ALP & $256.69 \pm 200.65$ & $121.72 \pm 49.01$ & 0.001 \\
\hline $24 \mathrm{hr}$ urine $\mathrm{Ca}$ & $577.21 \pm 238.30$ & $399.36 \pm 217.38$ & 0.021 \\
\hline Adenoma size & $22.67 \pm 15.72$ & $12.77 \pm 7.57$ & 0.006 \\
\hline \multicolumn{4}{|l|}{ USG } \\
\hline Hypoechoic & $12(75.0 \%)$ & $30(100 \%)$ & 0.016 \\
\hline Isoechoic & 2 (12.5\%) & - & \\
\hline Cystic & 2 (12.5\%) & - & \\
\hline \multicolumn{4}{|l|}{ MIBI } \\
\hline Positive & $12(75 \%)$ & $21(70.0 \%)$ & 0.72 \\
\hline Negative & $4(25 \%)$ & $9(30 \%)$ & \\
\hline PostopPTH & $45.61 \pm 65.20$ & $19.73 \pm 28.82$ & 0.068 \\
\hline PostopCa & $9.04 \pm 0.88$ & $8.60 \pm 0.72$ & 0.078 \\
\hline \multicolumn{4}{|l|}{ Recurrence } \\
\hline Present & 2 (12.5\%) & $1(3.3 \%)$ & 0.23 \\
\hline Absent & 14 (87.5\%) & 96.7 (96.7\%) & \\
\hline
\end{tabular}

\section{CONCLUSION}

> Preoperatively high PTH, ALP and urinary Ca levels may be predictive for atypical adenoma or carcinoma within a patient being evaluated for PHPT.

$>$ The surgeon might prefer enbloc parathyroidectomy instead of minimal invasive surgery in such cases with more strict postoperative follow up. 